\title{
Tobacco Control—Lighter Side: 30th Anniversary Cartoons
}

\section{Stan Shatenstein \\ Deputy News Editor, Tobacco Control}

For the past 30 years, Tobacco Control (TC) has been one of few leading scientific journals to include editorial cartoons in its pages. Any discussion of TC cartoons begins and ends with Mr Butts, who first appeared in Garry Trudeau's Doonesbury in April 1989, nearly 3 years before the inaugural edition of TC. The subject of a 1990 Doonesbury collection, You're Smokin' Now, Mr Butts!, he became so significant that, when the first batch of Brown and Williamson tobacco papers was delivered to UCSF (University of California at San Francisco), Professor Stanton Glantz in May 1974, the then-anonymous sender, listed 'Mr Butts' on the return address. Those papers became critical to research and litigation in the years and decades that followed, and they formed the basis for the UCSF's Legacy Tobacco Documents Library, now known as the Truth Tobacco Industry Documents archive.
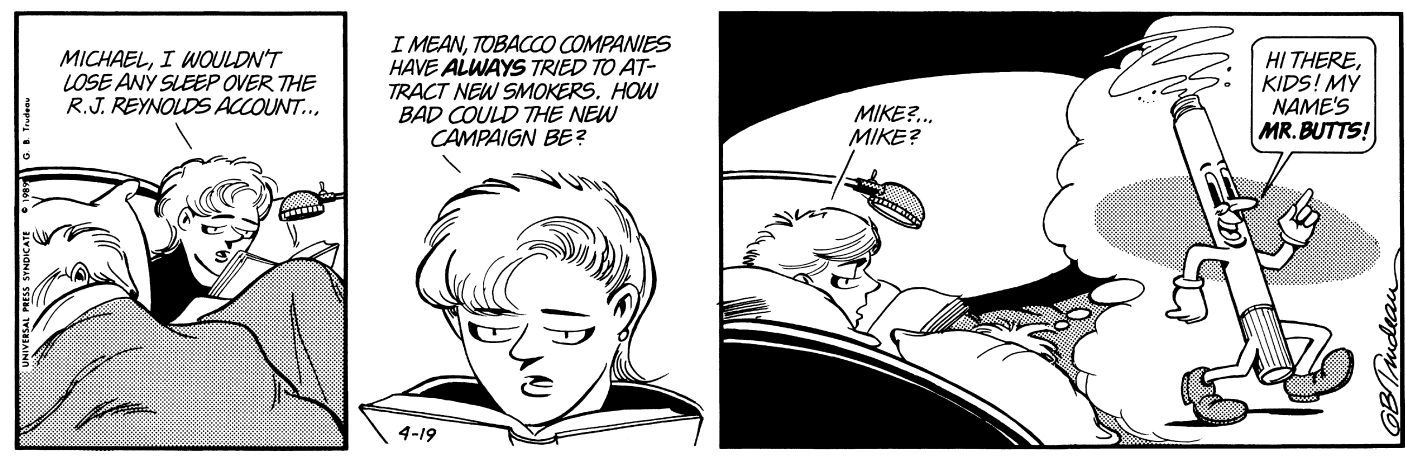

DOONESBURY (C) G.B. Trudeau. Reprinted with permission of ANDREWS MCMEEL SYNDICATION.

All rights reserved.

In 1992, for the 20th anniversary edition of TC, my colleague Dr Bert Hirschhorn and I looked back at the Best of The Lighter Side (1992-2009), so this collection focuses on cartoons appearing since 2010, with a classic or two appearing again.

\section{SECONDHAND SMOKE}

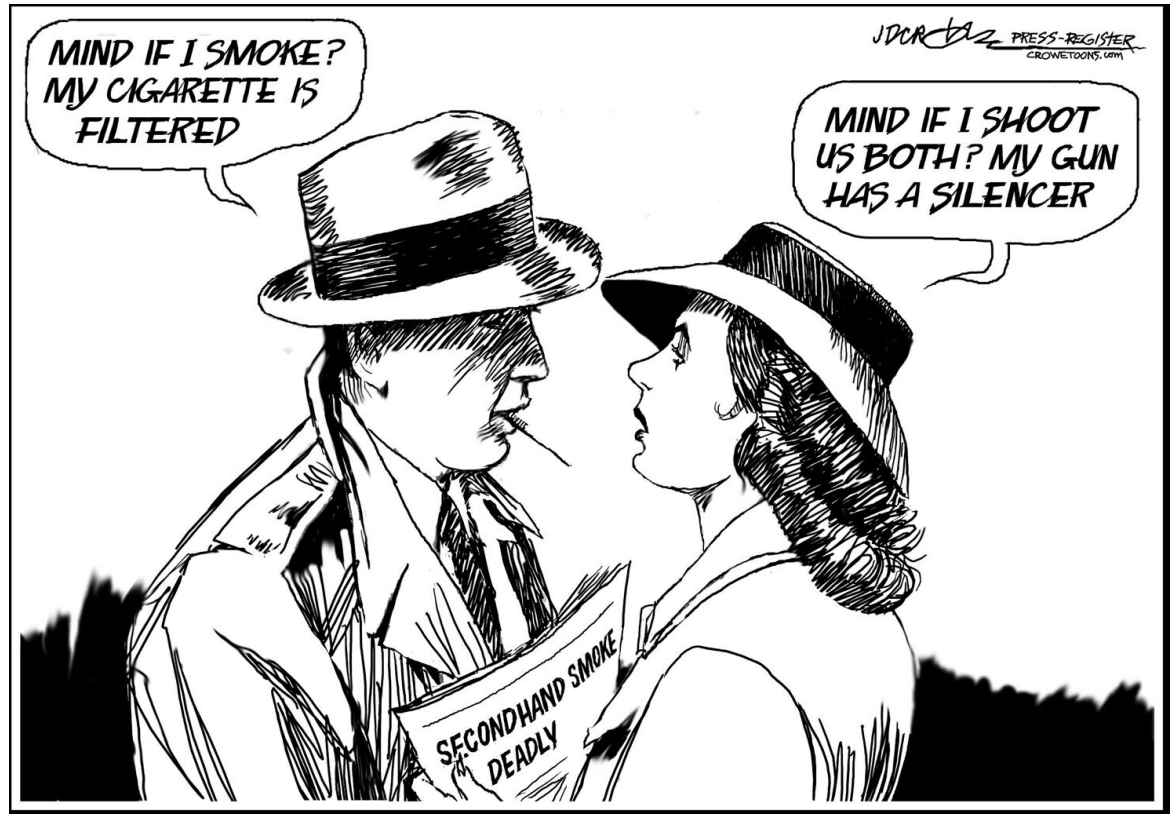

J.D. Crowe, Courtesy of Cagle Cartoons. 


\section{SMOKING \& THE ENVIRONMENT}

Even when it is pigeons ingesting cigarette butts, smoking is always a matter of life and death... even for animals.

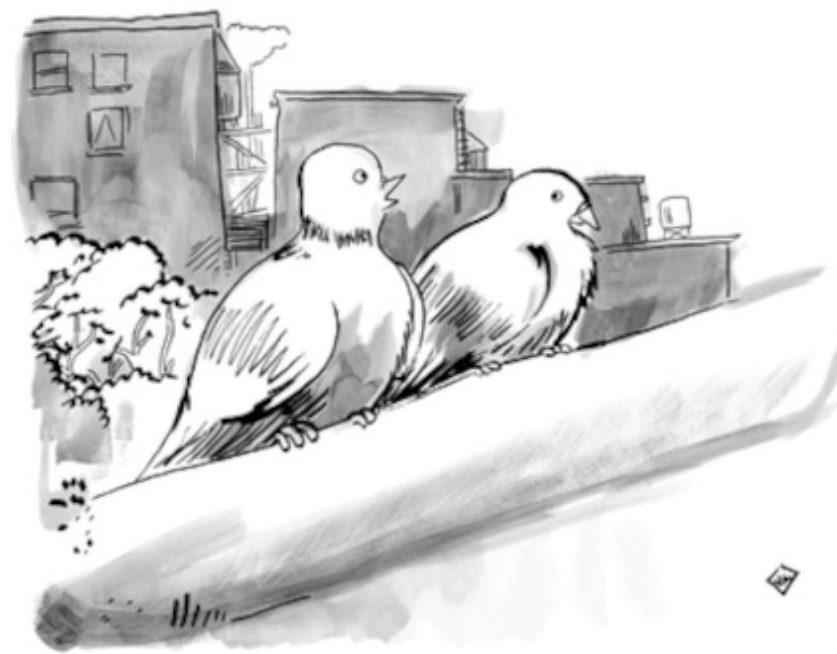

"My life bas really turned around since I quit eating cigarette butts."

John Leavitt/The New Yorker Collection/The Cartoon Bank.

MARKETING \& WOMEN

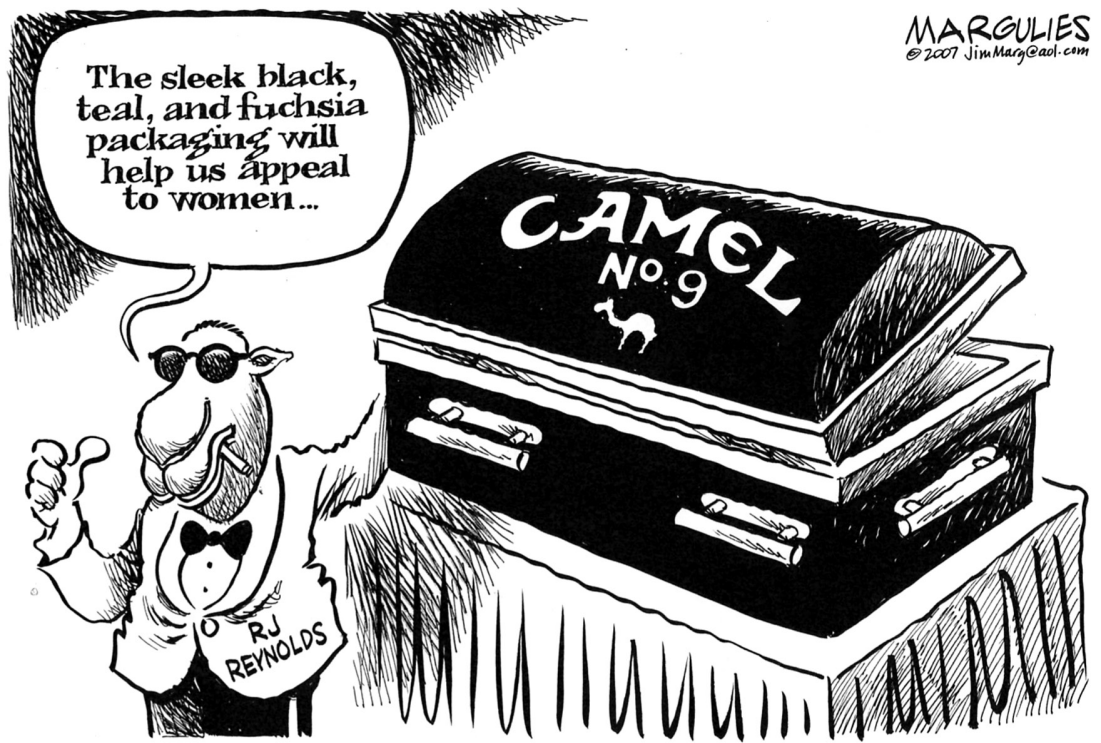

Margulies, Courtesy of Cagle Cartoons. 


\section{E-CIGARETTES}

The iconic '60s look of the TV show Mad Men from a decade ago adapted for the current vaping era.

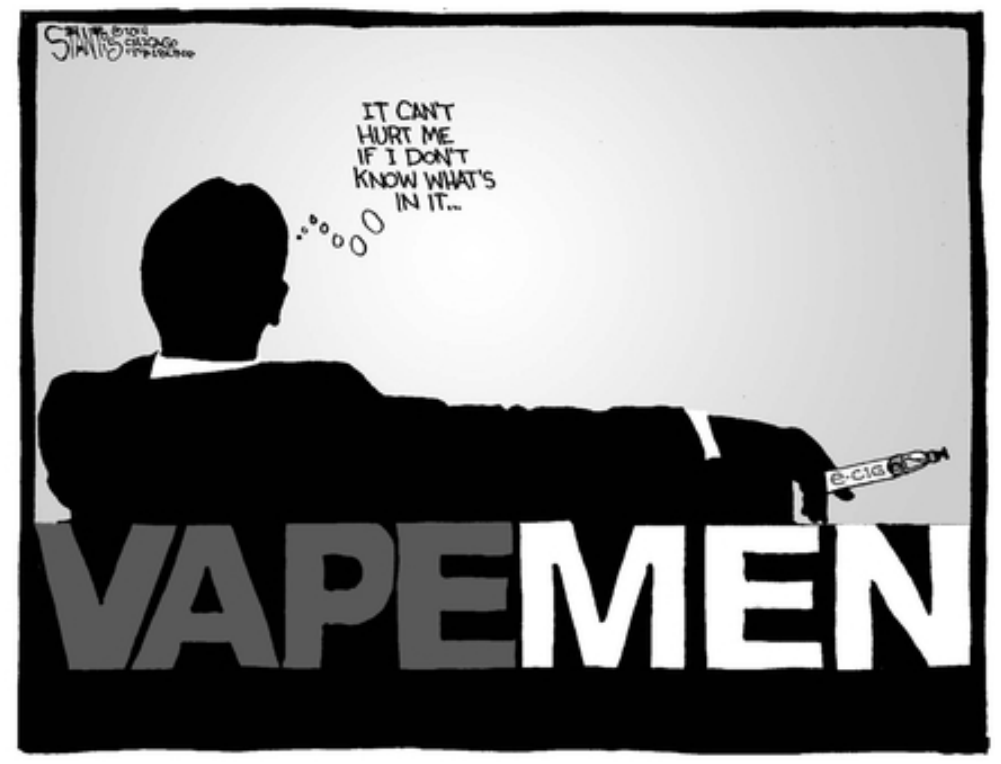

(C) 2019 Scott Stantis, All rights reserved. Distributed by Tribune Content Agency.

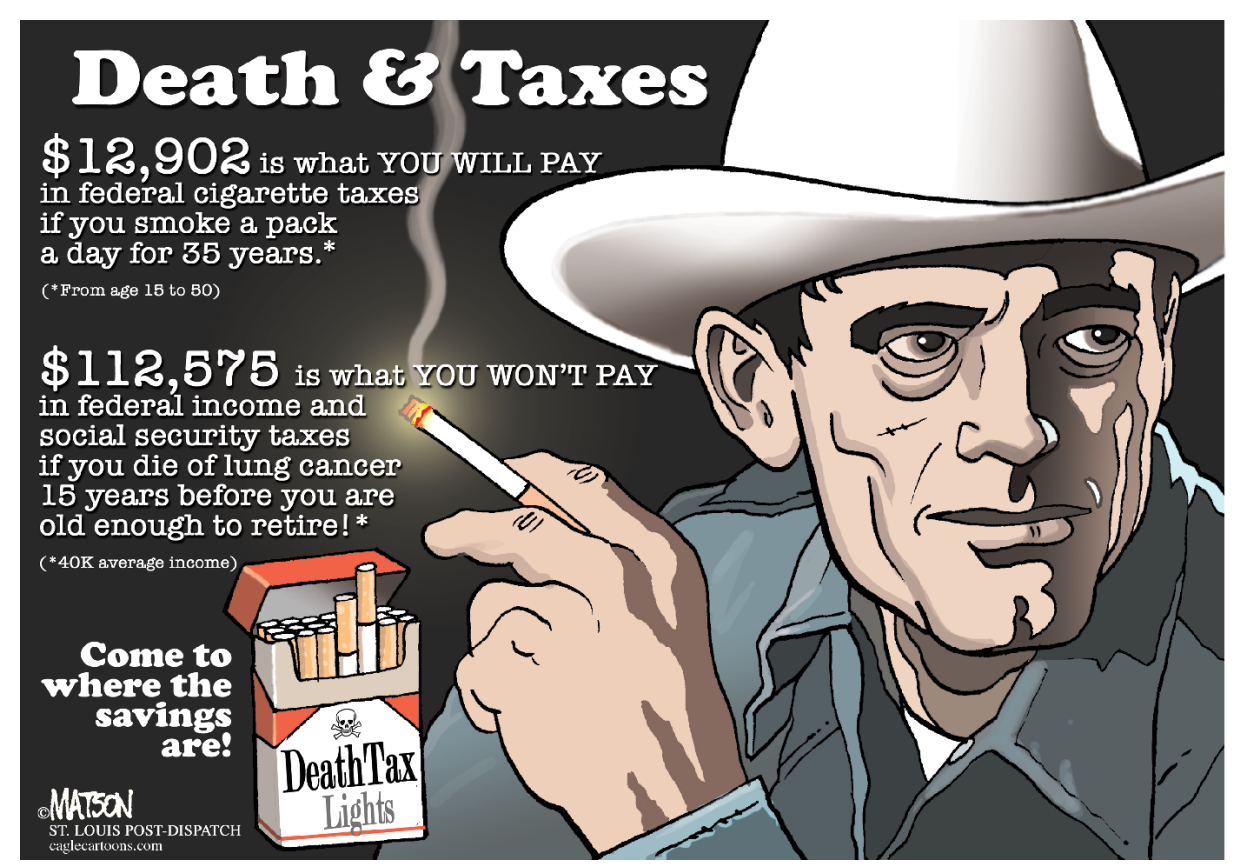

RJ Matson, Courtesy of Cagle Cartoons. 

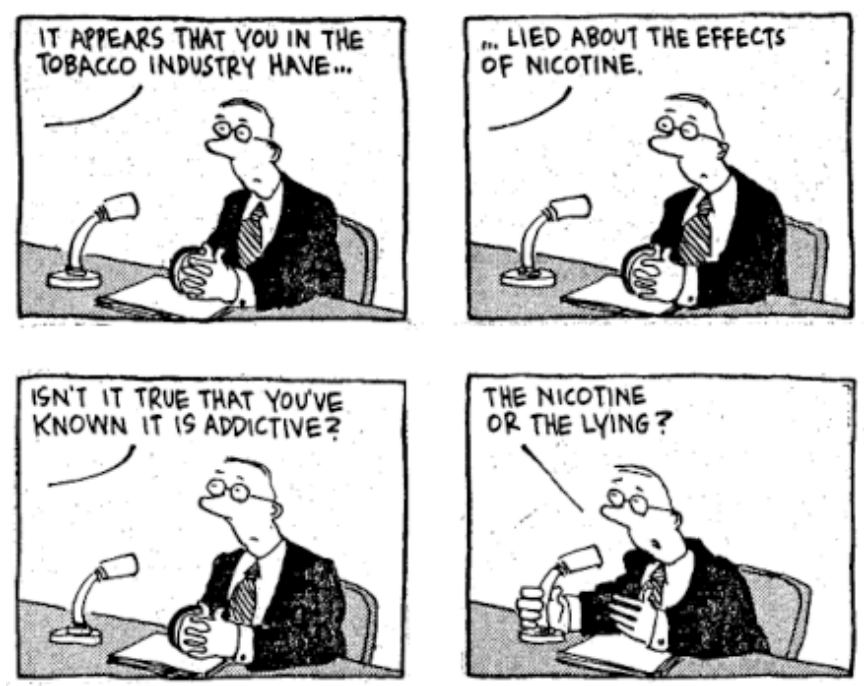

(C) Dan Wasserman, All rights reserved. Distributed by Tribune Content Agency.

\section{SMOKING AND THE MOVIES}

Long before Jurassic Park IV could be imagined, smoking had made a notable comeback in films like Avatar, where growing tobacco would have been near impossible or an extraordinary waste of precious agricultural land, and in the original Jurassic Park, Samuel L Jackson recalls that director Steven Spielberg gave him 'the worst-tasting fake cigarettes ever', knowing that Jackson had quit smoking and did not want to suffer a relapse in real life.

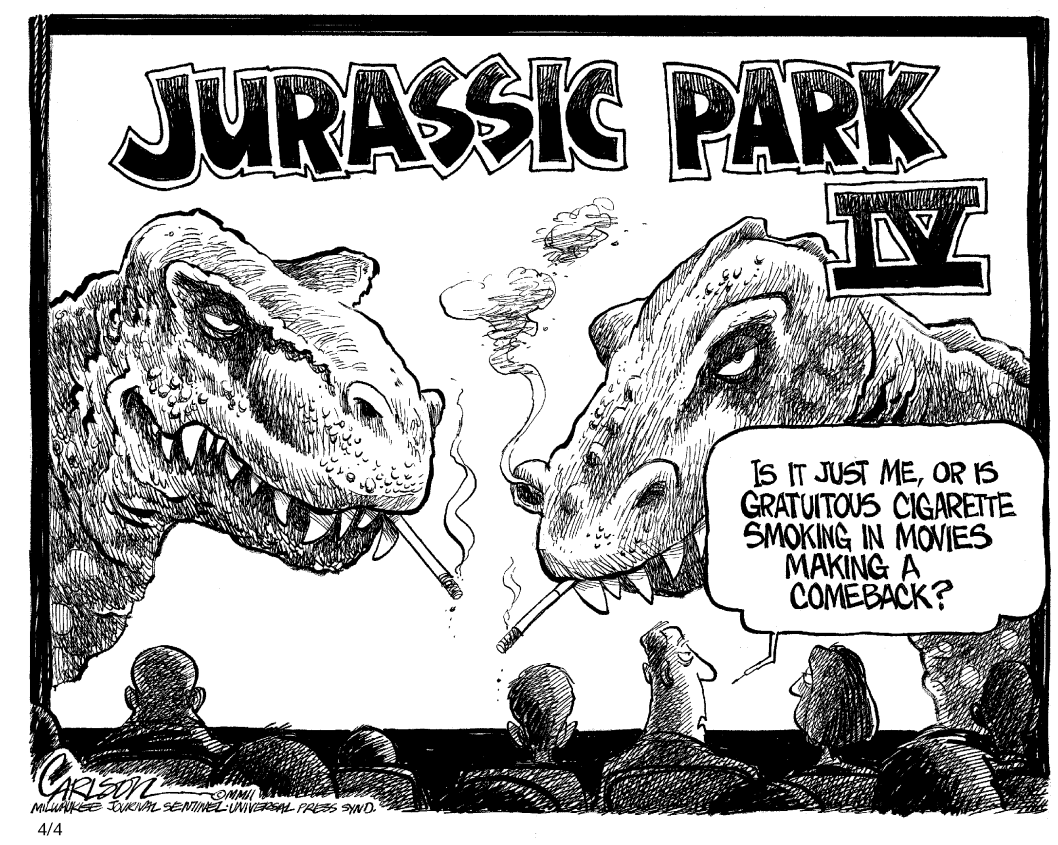

CARLSON (C) 2002 Milwaukee Journal Sentinel. Reprinted with permission of ANDREWS MCMEEL SYNDICATION. All rights reserved. 


\section{LAWSUITS}

In 2005, the Supreme Court of Canada unanimously upheld British Columbia's Tobacco Damages and Health Care Costs Recovery Act, making it possible for the province to continue to seek redress from the tobacco industry.

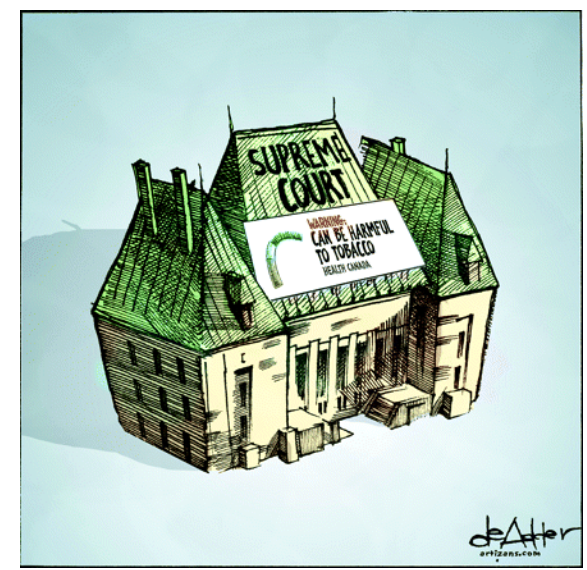

Michael de Adder - Artizans.com.

\section{SMOKING \& MORTALITY: TOBACCO DEATHS IN PERSPECTIVE}

In this era when COVID-19 is exerting a terrible toll on life across the planet, there have been inevitable comparisons to the banality of tobacco-related deaths, more than 7 million annually. In the past, some cartoonists have made the link. On a wall that echoes the appearance of the Vietnam Memorial in Washington, DC, the premature death of the heavy-smoking and popular ABC anchorman, the Canadian journalist Peter Jennings, puts a name to the mostly faceless list of the dead.

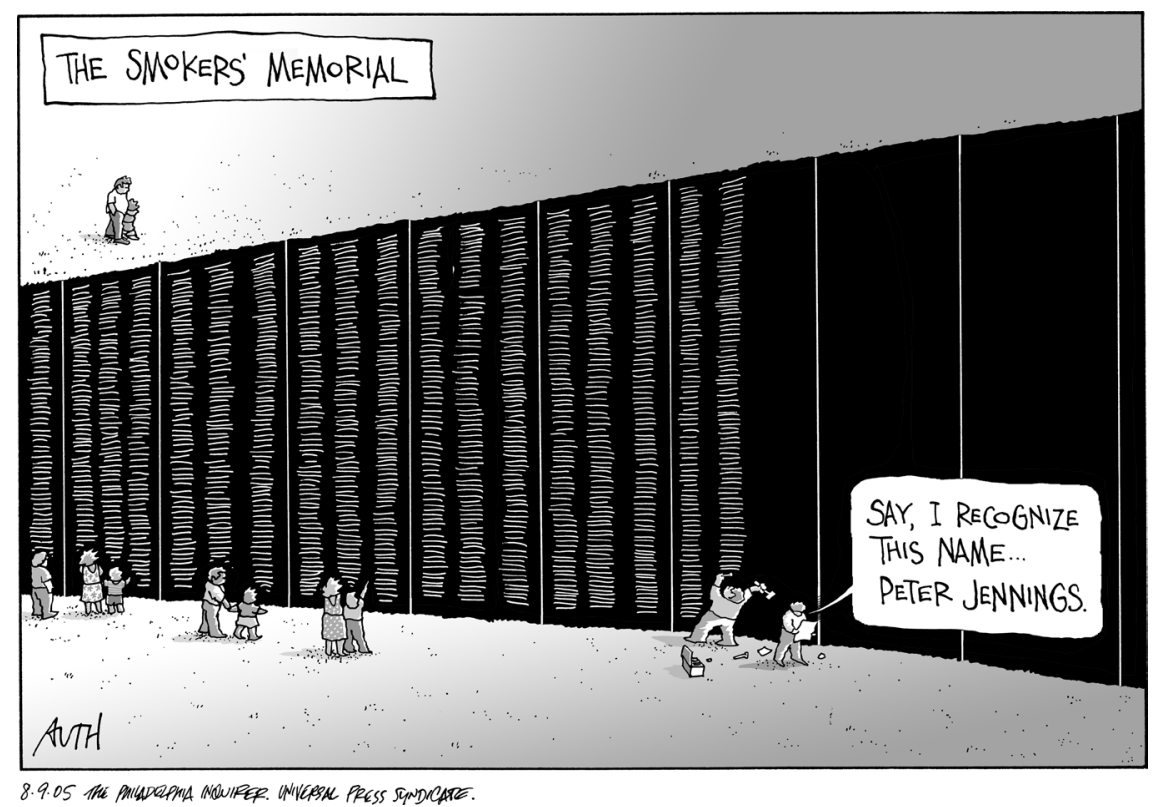

AUTH $\odot 2005$ The Philadelphia Inquirer. Reprinted with permission of ANDREWS MCMEEL SYNDICATION. All rights reserved. 
A different kind of pandemic. The cartoonist Monte Wolverton put tobacco deaths in perspective, comparisons again relevant, if delicate to make, in the COVID-19 era.

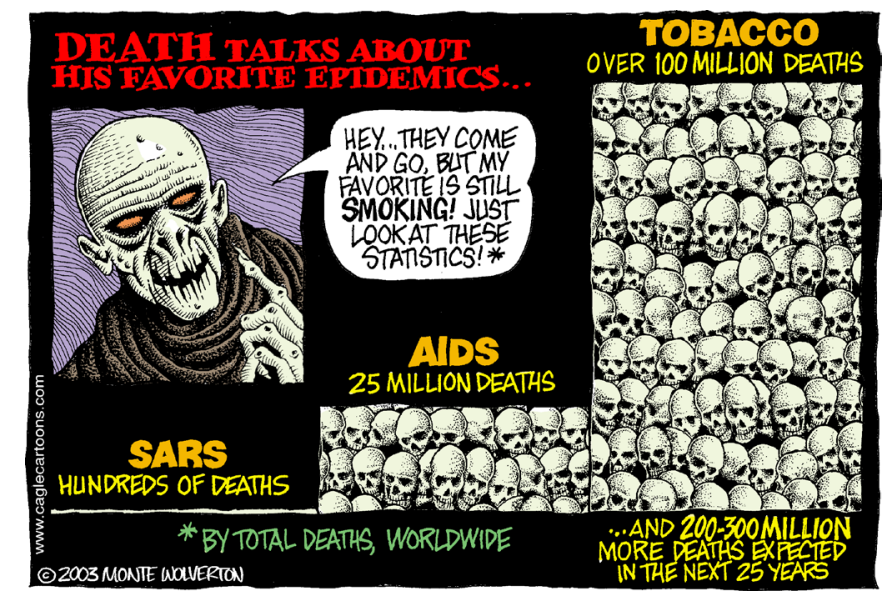

Monte Wolverton, Courtesy of Cagle Cartoons

\section{JUULY AND MR BUTTS}

Three decades after Mr Butts appeared on the scene, he meets his e-cigarette partner, Juuly, who echoes Donald Trump's reference to sh--hole countries.
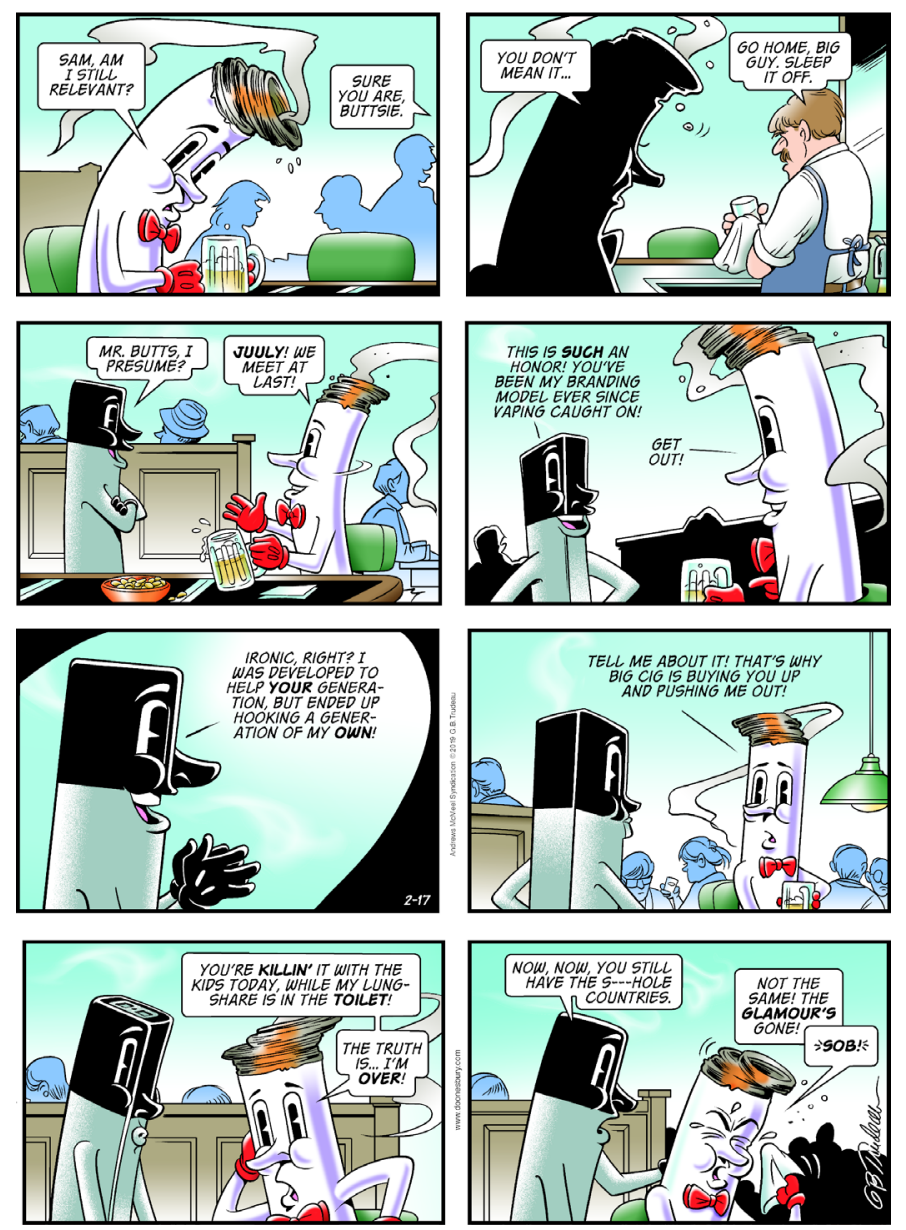

DOONESBURY () G.B. Trudeau. Reprinted with permission of ANDREWS MCMEEL SYNDICATION. All rights reserved. 
Contributors SS was the sole author.

Funding The authors have not declared a specific grant for this research from any funding agency in the public, commercial or not-for-profit sectors.

Competing interests None declared.

Patient consent for publication Not required.

Ethics approval This study does not involve human participants.

Provenance and peer review Not commissioned; externally peer reviewed.

ORCID iD

Stan Shatenstein http://orcid.org/0000-0002-5265-0967 